УДК 343.1

DOI: $10.35750 / 2071-8284-2019-4-107-112$

\author{
А.В. Никуленко \\ кандидат юридических наук, доцент \\ Санкт-Петербургский университет МВД России \\ Российская Федерация, 198206, Санкт-Петербург, ул. Лётчика Пилютова, д. 1 \\ ORCID: 0000-0003-1332-4621.E-mail:nikulenkoa@mail.ru

\section{Крайняя необходимость и её значение в оперативно-розыскной деятельности}

\begin{abstract}
Аннотация: Статья рассказывает о роли и месте обстоятельств, исключающих преступность деяния, в уголовном праве России. Демонстрируются возможности выполнения ими регулятивной функции деятельности сотрудников правоохранительных органов, в частности, сотрудников оперативных подразделений органов внутренних дел Российской Федерации. Основной акцент сделан на условиях правомерности причинения вреда при крайней необходимости как обстоятельстве, исключающем преступность деяния, в уголовном праве России. Затронуты вопросы применения нормы о крайней необходимости и её соотношении с условиями правомерности проведения оперативно-розыскных мероприятий сотрудниками правоохранительных органов. Подвергается критике действующий порядок правовой оценки проведения оперативно-розыскных мероприятий. Сделан вывод, что в настоящее время причинение вреда охраняемым уголовным законом интересам при проведении оперативно-розыскных мероприятий, с точки зрения его правомерности согласно нормам уголовного законодательства, может быть оправдано лишь крайней необходимостью. В связи с отсутствием пока соответствующих норм в действующем уголовном законодательстве следует ориентироваться на имеющуюся нормативную базу. Отмечается, что законодательство об оперативно-розыскной деятельности условий правомерности причинения вреда, к сожалению, не содержит. Таким образом, его роль в регулировании таковых отношений минимальна и не отвечает складывающейся правоприменительной практике. Предлагаются возможные пути разрешения указанных проблем.
\end{abstract}

Ключевые слова: уголовное право, уголовное законодательство, преступление, исключающие преступность деяния обстоятельства, крайняя необходимость, оперативно-розыскная деятельность, законодательство об оперативно-розыскной деятельности.

Для циитирования: Никуленко А.В. Крайняя необходимость и её значение в оперативно-розыскной деятельности // Вестник Санкт-Петербургского университета МВД России. - 2019. - № 4 (84). - C. 107-112. DOI: 10.35750/2071-8284-2019-4-107-112.

\author{
Andrei V. Nikulenko \\ Cand. Sci. (Jurid.), Docent \\ Saint-Petersburg University of the MIA of Russia \\ 1, Letchika Pilytova str., Saint-Petersburg, 198206, Russian Federation \\ ORCID: 0000-0003-1332-4621. E-mail: nikulenkoa@mail.ru
}

\title{
The extreme necessity and its importance in operational and investigative activities
}

Annotation: The article describes the role and place of circumstances precluding the criminality of the act in the criminal law of Russia. The authors demonstrate the possibilities of their regulatory function of law enforcement officers, in particular, employees of operational units of the internal Affairs bodies of the Russian Federation. The main emphasis is placed on the conditions of legality of causing harm in case of extreme necessity, as a circumstance precluding the criminality of the act, in the criminal law of Russia. The questions of application of the norm of extreme necessity and its correlation with the conditions of legality of operational search activities by law enforcement officers are touched upon. The current procedure of legal assessment of operational search activities is criticized. It is concluded that at present the harm to the interests protected by the criminal law during the operational search activities, from the point of view of its legality to the norms of the criminal legislation, can be justified only by extreme necessity. Due to the lack of relevant norms in the current criminal legislation, it is necessary to focus on the existing regulatory framework. It is noted that the legislation on operational-search activity of conditions of legality of causing harm, unfortunately, does not contain. Thus, its role in the regulation of such relations is minimal and does not meet the prevailing law enforcement practice. Possible solutions to these problems are proposed. 
Keywords: criminal law, criminal legislation, crime, circumstances precluding the criminality of the act, extreme necessity, operational-search activity, legislation on operational-search activity.

For citation: Nikulenko A.V. The extreme necessity and its importance in operational and investigative activities // Vestnik of St. Petersburg University of the Ministry of Internal Affairs of Russia. - 2019. - № 4 (84). - P. 107-112. DOI: 10.35750/2071-8284-2019-4-107-112.

Проведение оперативно-розыскных мероприятий непременно сопровождается риском. Этот риск заключается в отсутствии скольнибудь определённых условий правомерности, регламентирующих проведение того или иного мероприятия. По мнению В. Н Боркова, «содержание оперативно-розыскной деятельности и условия правомерности осуществляемых в её рамках мероприятий регламентируются Федеральным законом от 12 августа 1995 г. № 144ФЗ» ${ }^{1}$. Заметим, что это далеко не так.

По мнению ряда представителей наук криминального цикла, вышеуказанный закон не оправдал надежд, возлагавшихся на него в связи с его принятием. Так, например, ст. 6 Закона содержит лишь перечень оперативно-розыскных мероприятий. Другие нормы этого Закона носят явно декларативный характер, так как не учитывают ни обстановки их проведения, ни, разумеется, условий их правомерности. В то же время пресловутая ч. 4 ст. 16 Закона декларирует: «При защите жизни и здоровья граждан, их конституционных прав и законных интересов, а также для обеспечения безопасности общества и государства от преступных посягательств допускается вынужденное причинение вреда правоохраняемым интересам должностным лицом органа, осуществляющего оперативно-розыскную деятельность, либо лицом, оказывающим ему содействие, совершаемое при правомерном выполнении указанным лицом своего служебного или общественного долга».

Таким образом, данная норма содержит в себе не что иное, как обстоятельство, исключающее преступность деяния, которому должно находиться в ткани уголовного законодательства и содержать хотя бы общие условия правомерности причинения вреда охраняемым уголовным законом интересам. Определение преступности и наказуемости деяний, а также непреступности того или иного деяния является исключительной прерогативой Уголовного кодекса Российской Федерации, а никак не других нормативных правовых актов. Существование таковых норм в ином (не уголовном) законодательстве ставит под угрозу конституционные права и интересы граждан, а также существенно затрудняет исполнение государством правоохранительной функции по выявлению и раскрытию преступлений, значительно сужая возможности оперативно-розыскной деятельности и сковывая инициативу оперативных работников.

${ }^{1}$ Борков В. Н. Уголовно-правовая оценка включённости участника оперативно-розыскного мероприятия в преступление // Вестник Санкт-Петербургского университета МВД России. - 2019. - № 3. - С. 98.
Но вернёмся к риску, который существует прежде всего для сотрудников, осуществляющих то или иное оперативно-розыскное мероприятие. Этот риск нами связывается с наличием угрозы наступления уголовно-правовых последствий в виде привлечения такового оперативного работника к уголовной ответственности. Для нас представляется очевидным, что, если сфера правомерного причинения вреда интересам, охраняемым уголовным законом, должным образом нормативно не урегулирована, существует реальная опасность объективного вменения в вину нарушения условий проведения того или иного оперативно-розыскного мероприятия, что, несомненно, повлечёт за собой уголовно-правовые последствия. А ведь нарушены «всего лишь» несуществующие нормы Закона «Об ОРД».

В настоящее время, с точки зрения уголовного закона, оправдать проведение практически любого оперативно-розыскного мероприятия возможно лишь применяя положения норм главы 8 УК России. Но их явно недостаточно в уголовном законе, к тому же они не отражают специфики проведения конкретного оперативно-розыскного мероприятия, и потому малоприменимы в реальной обстановке.

Стоит, правда, заметить, что проблемы правоприменительной деятельности зачастую лежат именно в законодательной плоскости, и мнения о возможности достижения целей оперативно-розыскной деятельности без тщательной регламентации действий её субъектов считаем не вполне обоснованными, так как именно отсутствие чётких критериев правомерности таковых действий создаёт как почву для злоупотреблений со стороны оперативных сотрудников, так и возможности для их уголовного преследования со стороны контролирующих и надзирающих за оперативно-розыскной деятельностью органов. Таким образом, мы настаиваем на уголовно-правовой регламентации всех обстоятельств, при наличии которых причинение вреда охраняемым уголовным законом интересам признаётся правомерным ${ }^{2}$.

Кстати, именно так поступил казахский законодатель, включив, правда, в Уголовнопроцессуальный кодекс Казахстана соответствующую главу 30 «Негласные следственные действия» (ст. 231-251), предусмотрев в качестве таковых в ст. 231: «1) негласные аудио- и (или)

${ }^{2}$ Никуленко А. В. Обстоятельства, исключающие преступность деяния: концептуальные основы уголовно-правовой регламентации : автореф. дис. ... д-ра юрид наук: 12.00.08 / Никуленко Андрей Вячеславович. - СанктПетербург, 2019. - С. 9-18. 
видеоконтроль лица или места; 2) негласные контроль, перехват и снятие информации, передающейся по сетям электрической (телекоммуникационной) связи; 3 ) негласное получение информации о соединениях между абонентами и (или) абонентскими устройствами; 4) негласное снятие информации с компьютеров, серверов и других устройств, предназначенных для сбора, обработки, накопления и хранения информации; 5) негласный контроль почтовых и иных отправлений; 6) негласные проникновение и (или) обследование места; 7) негласное наблюдение за лицом или местом; 8) исключён в соответствии с Законом РК от 3 июля 2017 г. № 84-VI; 9) негласный контрольный закуп; 10) негласные внедрение и (или) имитация преступной деятельности» ${ }^{3}$. Введены соответствующие нормы и в Уголовно-процессуальный кодекс Кыргызской Республики 4 .

Пока необходимой, на наш взгляд, модернизации норм главы 8 Уголовного кодекса России не произошло, попробуем использовать возможности имеющихся в нашем распоряжении действующих норм.

Отметим, что нами предложена соответствующая норма ${ }^{5}$. Речь идет о «Правомерной провокации», призванной бороться прежде всего с преступлениями в сфере незаконного оборота наркотических средств и взяточничества. В сущности, она может получить и другое название, например, «Оперативный эксперимент», так как регламентирует именно его проведение. Другие нормы действующего УК - необходимая оборона и причинение вреда при задержании лица, совершившего преступление - не вполне вписываются (в имеющейся редакции) в рамки осуществления оперативно-розыскных мероприятий. И всё же, помимо состояния необходимой обороны, в жизни складываются ситуации, когда, во-первых, источник опасности, угрожающей правоохраняемым интересам, коренится именно в порицаемом обществом поведении человека; во-вторых, однако, избирается принципиально иной способ защиты социально значимых благ - не путём причинения вреда посягающему, а за счёт ущемления других законных интересов общества, государства и граждан. Речь идёт об институте крайней необходимости.

Впервые упоминание о крайней необходимости сложилось в средние века с появлением

${ }^{3}$ Уголовно-процессуальный кодекс Республики Казахстан от 4 июля 2014 года № $231-\mathrm{V}$ (с изменениями и дополнениями по состоянию на 01.04.2019 г.) Интернет-ресурс: https://online.zakon.kz/m/document?doc_id=31575852\#sub_ $\mathrm{id}=2310000$. Дата обращения: 07 ноября 2019 г.

${ }_{4}^{4}$ Уголовно-процессуальный кодекс Кыргызской Республики от 2 февраля 2017 года № 20 (Вводится в действие Законом КР от 24 января 2017 года № 10 с 1 января 2019 года) (В редакции Закона КР от 15 мая 2019 года № 62). Интернет-ресурс: http://cbd.minjust.gov.kg/act/view/ ru-ru/111530. Дата обращения 11 ноября 2019 г. (См.: глава 31. Специальные следственные действия).

${ }_{5}^{5}$ Никуленко А. В. Обстоятельства, исключающие преступность деяния: концептуальные основы уголовноправовой регламентации : автореф. дис. ... д-ра юрид наук. - Санкт-Петербург, 2019. - С. 16. таких понятий, как «нужда закона не знает», «что не дозволено законом, делает дозволенной необходимость» и т. д. Для состояния крайней необходимости характерно столкновение двух интересов, когда для спасения более ценного блага человек жертвует менее ценным благом. Следует согласиться с мнением, что в этическом плане институт необходимой обороны и даже причинения вреда при задержании преобладает над институтом крайней необходимости. Особенно это проявляется при устранении опасности, угрожающей не интересам других лиц, общества и государства, а исключительно своим личным интересам. Согласно позиции В. Н. Винокурова, охрана интересов общества и государства, а также посторонних лиц более полезна, чем охрана собственных интересов [1, с. 119].

Представляет интерес дискуссионный вопрос о содержании признака опасности как «непосредственно угрожающей», прямо указанного в законе. Нами и профессором С. Ф. Милюковым уже высказывалось предложение об исключении данного признака из законодательной формулировки ст. 39 УК [2, с. 66; 3, с. 233]. Мы полагаем, что недопустимо оправдывать состоянием крайней необходимости невыполнение правовой обязанности, например, чтобы не погибнуть, пожарный отказывается тушить огонь, солдат - идти в атаку, сотрудник правоохранительных органов - задерживать преступника. Впрочем, заметим, что в том числе вследствие отсутствия необходимой регламентации полицейские и так проявляют неоправданную пассивность, предпочитая не рисковать и уходить от конфликтов, неизбежно возникающих в правоохранительной деятельности. Такие действия (если быть точнее - бездействие) влекут за собой уголовную ответственность по ст. 285 УК или образуют состав воинского преступления. Соглашаясь с тем, что ситуация крайней необходимости возможна и при пассивной форме поведения человека, мы считаем, что отдельные положения ст. 39 УК не распространяются на лиц, которые в силу своей юридической обязанности или служебного долга должны бороться с угрожающей опасностью ${ }^{6}$. Примечательна в этом плане позиция испанского законодателя, закрепившего правило, по которому крайняя необходимость действует «если состояние необходимости не было спровоцировано лицом, причинившим вред». Данное положение в той или иной форме закреплено в законодательстве Германии, США (штат Нью-Йорк), Республики Польша.

Мотивами крайней необходимости могут быть жалость, сострадание, боязнь, страх, альтруизм, сознание гражданского и общественного долга, стремление оказать помощь, желание отличиться, заслужить похвалу или вознаграждение и др., которые вообще-то на оценку содеянного не влияют, но могут быть учтены судом

${ }^{6}$ Никуленко А. В. Роль обстоятельств, исключающих преступность деяния, в современных реалиях противодействия преступности // Вестник Санкт-Петербургского университета МВД России. - 2017. - № 2 (74). - С. 105. 
при решении вопроса об ответственности при превышении пределов крайней необходимости ${ }^{7}$.

Что же касается физических и психических особенностей лица, действующего в экстремальной ситуации, то здесь необходимо учитывать целый ряд факторов: образовательный уровень, возрастную, половую, демографическую принадлежность, медицинские показатели и др. Кроме того, при возникновении малейшего сомнения в полноценности восприятия лицом имевшей место ситуации или способности адекватного поведения предлагается проведение освидетельствования и экспертизы. Далее, мы предлагаем чётко закрепить в самом законе цель крайней необходимости - устранить грозящую опасность [4, с. 205-206].

Заслуживает внимания предлагаемая рядом авторов реконструкция ст. 39 УК РФ, хотя при пристальном рассмотрении выясняется, что и она не лишена некоторых недостатков. Часть 1 указанной статьи предлагается сформулировать следующим образом: «Не совершает преступления тот, кто причиняет вред охраняемым уголовным законом интересам в состоянии крайней необходимости» $[5, \text { с. } 122 ; 6, \text { с. } 322]^{8}$. На наш взгляд, использование в законе конструкций «тот, кто» выглядит неуместным, поскольку не соответствует традициям отечественного нормотворчества, являясь прямым заимствованием зарубежного правового стиля и дореволюционной законотворческой практики [7, с. 311]. Зато целесообразным выглядит включение в текст статьи следующего установления: «Крайней необходимостью признается также такое состояние, при котором деяние, совершенное с целью устранения угрожающей опасности неизбежного причинения вреда правоохраняемым интересам, не достигло этой цели и предотвращаемый вред наступил, несмотря на усилия лица, добросовестно рассчитывающего его предотвратить путём причинения менее значительного вреда». В этом контексте можно поставить в пример УК Республики Беларусь (ст. 36), содержащее соответствующее положение [8, с. 174].

Следует признать, что в уголовном законе отсутствует привилегированная норма, предусматривающая уголовную ответственность не только за превышение пределов крайней необходимости, но и иных обстоятельств, исключающих преступность деяния. Так как в Особенной части Уголовного кодекса России отсутствует таковая норма (как это сделано для необходимой обороны и причинении вреда при задержании), вполне приемлемым выглядит предложение о квалификации действий виновного при превышении пределов крайней необходимости со ссылкой на ст. 39 УК РФ [9, с. 770-771].

${ }^{7}$ Никуленко А В. Актуальные проблемы разграничения институтов крайней необходимости и причинения вреда при задержании лица, совершившего преступление // Вестник Санкт-Петербургского университета МВД России. - 2010. - № 4. - С. 76.

${ }^{8}$ Впервые данную формулировку предложила проф. С. В. Пархоменко, а впоследствии дословно воспроизвёл в своей работе М. А. Якуньков.
Возможно распространение этой практики на другие обстоятельства, исключающие преступность деяния, также не получившие поддержки законодателя в Особенной части УК, хотя считаем нелишним рассмотреть в этом ключе вопрос о дополнении Особенной части УК соответствующей статьёй, посвящённой указанному обстоятельству, наряду со ст. 108 и 114 УК РФ [10, с. 161-165]. Столь же плодотворна идея об усовершенствовании ст. 61 УК РФ включением самостоятельного обстоятельства, смягчающего наказание: «причинение в состоянии крайней необходимости вреда, равного предотвращённому».

В ряде случаев на практике не просто определить, имело ли место превышение пределов крайней необходимости. Прежде всего это касается ситуаций, когда причинённый вред по своему характеру резко отличается от вреда, который способна нанести грозящая опасность. При оценке не следует механически подходить к соотношению жертвуемого и оберегаемых благ. Скажем, принесение в жертву одной или даже нескольких человеческих жизней ради доставления транспорта с продовольствием в голодающий северный посёлок с населением несколько сотен человек вполне оправданно (естественно, при наличии всех остальных условий правомерности причинения вреда в состоянии крайней необходимости).

Возвращаясь непосредственно к оперативно-розыскным мероприятиям и условиям их правомерности, отметим, что в настоящее время лишь крайняя необходимость может выступать законным основанием для проведения таких мероприятий, как: проверочная закупка; обследование помещений, зданий, сооружений, участков местности и транспортных средств; контроль почтовых отправлений, телеграфных и иных сообщений; прослушивание телефонных переговоров; снятие информации с технических каналов связи; оперативное внедрение; контролируемая поставка; оперативный эксперимент; получение компьютерной информации.

Пока только крайней необходимостью с точки зрения закона можно оправдать нарушение конституционных прав граждан на свободу и неприкосновенность жилища, тайну переписки и других. Причём неважно, совершаются таковые действия открыто или негласно, втайне от гражданина.

Закон запрещает причинять вред правоохраняемым законом интересам ради спасения равноценных благ. Так, преступным будет спасение собственной жизни за счёт жизни другого человека. В то же время, мы полагаем, возможности крайней необходимости не исчерпываются вышеуказанными случаями. Так, на крайнюю необходимость ссылаются полицейские, останавливающие автомобиль путём его повреждения, военнослужащие Федеральной пограничной службы ФСБ России, уничтожающие водное или воздушное судно, нарушившее режим Государственной границы России, воздушного пространства или территориальных 
вод Российской Федерации, а также пожарные, разрушающие горящую постройку с целью не допустить дальнейшего распространения огня.

По справедливому мнению ряда учёных, «...противоречия и пробелы между двумя науками (имеются ввиду уголовное право и оперативно-розыскная деятельность - А.Н.) указывает на то, что в их основе находится взаимное недостаточное внимание в двух доктринах. При этом большая доля ответственности в сложившейся ситуации лежит на представителях теории уголовного права. За более чем 25-летний период действия оперативно-разыскного законодательства уголовно-правовая доктрина фактически игнорировала проблемы оперативно-разыскной деятельности. Поэтому в современных условиях противодействия преступности данное направление комплексных научных изысканий нам представляется одним из самых востребованных» $[11$, с. 88$]$.

В завершение представляем авторскую норму о крайней необходимости:

«Статья 39. Крайняя необходимость.

1. Не является преступлением причинение вреда охраняемым уголовным законом интересам в состоянии крайней необходимости, в целях устранения опасности, угрожающей личности и правам данного лица или иных лиц, охраняемым законом интересам общества или государства, если эта опасность не могла быть устранена без причинения вреда и при этом не было допущено превышения пределов крайней необходимости, т. е. умышленных действий, явно не соответствующих характеру и степени угрожавшей опасности, когда указанным интересам был причинён вред равный или более значительный, чем предотвращённый.

2. При оценке правомерности причинения вреда при крайней необходимости учитываются, наряду с характером и степенью угрожавшей опасности, силы и возможности субъекта крайней необходимости, его психическое состояние и иные обстоятельства, связанные с фактом причинения вреда при устранении опасности.

3. Не подлежит уголовной ответственности лицо, которое в силу неожиданности опасности, замешательства, испуга, страха или по другим обстоятельствам находилось в состоянии душевного волнения и потому превысило пределы мер, необходимых для устранения опасности.

4. Крайней необходимостью признается также такое состояние, при котором деяние, совершённое с целью устранения угрожающей опасности неизбежного причинения вреда правоохраняемым интересам, не достигло этой цели, и предотвращаемый вред наступил, несмотря на усилия лица, добросовестно рассчитывающего его предотвратить путём причинения менее значительного вреда.

5. Превышение пределов крайней необходимости влечёт уголовную ответственность только в случаях умышленного причинения вреда.

6. Крайняя необходимость не является основанием для отказа от выполнения юридической обязанности или исполнения служебного долга, состоящих в действиях по устранению опасности».

\section{Список литературь}

1. Винокуров В. Н. Правомерное причинение вреда в состоянии крайней необходимости : монография. - Красноярск : Сибирский юрид. ин-т МВД России, 2001. - 119 с.

2. Милюков С. Ф., Сиятскова Л. А. Необходимая оборона по уголовному законодательству России как элемент гражданской самозащиты : монография. - Новгород: Мир, 2005. - 247 с.

3. Никуленко А. В. Совершенствование уголовного законодательства об обстоятельствах, исключающих преступность деяния / Уголовное право: стратегия развития в XXI веке : материалы XIV международной научно-практической конференции. - Москва: Проспект, 2017. - С. 232-236.

4. Никуленко А. В. Обстоятельства, исключающие преступность деяния и возможности их модернизации / Уголовная политика и правоприменительная практика : сб. ст. по материалам IV Bceрос. науч.-практич. конференции / отв. ред. Е. Н. Рахманова. - Санкт-Петербург : ИД «Петрополис», 2016. - C. 205-211.

5. Пархоменко С. В. Деяния, преступность которых исключается в силу социальной полезности и необходимости : монография. - Санкт-Петербург : Юридический центр Пресс, 2004. - 267 с.

6. Якуньков М. А. Крайняя необходимость / Энциклопедия уголовного права. - Т. 7. / 2-е изд. Санкт-Петербург : ГКА, 2014. - 722 с.

7. Милюков С. Ф., Никуленко А. В. Новейшие подходы к изучению проблем правовой регламентации обстоятельств, исключающих преступность деяния // Российский криминологический взгляд. - 2008. - № 3. - С. 310-319.

8. Никуленко А. В. Перспективы совершенствования уголовно-правовых норм об обстоятельствах, исключающих преступность деяния / Проблемы кодификации уголовного закона: история, 
современность, будущее (посвящ. 200-летию проекта Уголовного уложения 1813 года) : материалы VIII Российского конгресса уголовного права. - Москва: Проспект, 2013. - С. 172-177.

9. Милюков С. Ф., Никуленко А. В. Современные проблемы правового регулирования обстоятельств, исключающих преступность деяния // Российский ежегодник уголовного права. - 2008. - № 2. - С. 764-796.

10. Никуленко А. В. О возможностях модернизации дозволительных норм УК России / Уголовная политика и правоприменительная практика : сб. ст. по материалам Всерос. научн.-практ. конференции / отв. ред.: Е. Н. Рахманова. - Санкт-Петербург : ИД «Петрополис», 2014. - С. 161-165.

11. Плешаков А. М., Шкабин Г. С. Проблемы научных изысканий в сфере взаимосвязи уголовного права и оперативно-разыскной деятельности / Уголовное право и оперативно-разыскное законодательство: проблемы между отраслевых связей и перспективы совершенствования : материалы IV межведомственной научно-практической конференции (Рязань, 30 ноября 2018 г.) / отв. ред. В. П. Кувалдин. - Москва : ИД «Юриспруденция», 2019. - С. 85-89.

\section{References}

1. Vinokurov V. N. Pravomernoye prichineniye vreda $\mathrm{v}$ sostoyanii krayney neobkhodimosti : monografiya. - Krasnoyarsk : Sibirskiy yurid. in-t MVD Rossii, 2001. - 119 s.

2. Milyukov S. F., Siyatskova L. A. Neobkhodimaya oborona po ugolovnomu zakonodatel'stvu Rossii kak element grazhdanskoy samozashchity : monografiya. - Novgorod: Mir, 2005. - 247 s.

3. Nikulenko A. V. Sovershenstvovaniye ugolovnogo zakonodatel'stva ob obstoyatel'stvakh, isklyuchayushchikh prestupnost' deyaniya / Ugolovnoye pravo: strategiya razvitiya v XXI veke : materialy XIV mezhdunarodnoy nauchno-prakticheskoy konferentsii. - Moskva: Prospekt, 2017. - S. 232-236.

4. Nikulenko A. V. Obstoyatel'stva, isklyuchayushchiye prestupnost' deyaniya i vozmozhnosti ikh modernizatsii / Ugolovnaya politika i pravoprimenitel'naya praktika : sb. st. po materialam IV Vseros. nauch.praktich. konferentsii / otv. red. Ye. N. Rakhmanova. - Sankt-Peterburg: ID «Petropolis», 2016. - S. 205-211.

5. Parkhomenko S. V. Deyaniya, prestupnost' kotorykh isklyuchayetsya v silu sotsial'noy poleznosti i neobkhodimosti : monografiya. - Sankt-Peterburg : Yuridicheskiy tsentr Press, 2004. - 267 s.

6. Yakun'kov M. A. Kraynyaya neobkhodimost' / Entsiklopediya ugolovnogo prava. - T. 7. / 2-ye izd. Sankt-Peterburg: GKA, 2014. - 722 s.

7. Milyukov S. F., Nikulenko A. V. Noveyshiye podkhody k izucheniyu problem pravovoy reglamentatsii obstoyatel'stv, isklyuchayushchikh prestupnost' deyaniya // Rossiyskiy kriminologicheskiy vzglyad. - 2008. - № 3. - S. 310-319.

8. Nikulenko A. V. Perspektivy sovershenstvovaniya ugolovno-pravovykh norm ob obstoyatel'stvakh, isklyuchayushchikh prestupnost' deyaniya / Problemy kodifikatsii ugolovnogo zakona: istoriya, sovremennost', budushcheye (posvyashch. 200-letiyu proyekta Ugolovnogo ulozheniya 1813 goda) : materialy VIII Rossiyskogo kongressa ugolovnogo prava. - Moskva: Prospekt, 2013. - S. 172-177.

9. Milyukov S. F., Nikulenko A. V. Sovremennyye problemy pravovogo regulirovaniya obstoyatel'stv, isklyuchayushchikh prestupnost' deyaniya // Rossiyskiy yezhegodnik ugolovnogo prava. - 2008. - № 2. S. 764-796.

10. Nikulenko A. V. O vozmozhnostyakh modernizatsii dozvolitel'nykh norm UK Rossii / Ugolovnaya politika i pravoprimenitel'naya praktika : sb. st. po materialam Vseros. nauchn.-prakt. konferentsii / otv. red.: Ye. N. Rakhmanova. - Sankt-Peterburg: ID «Petropolis», 2014. - S. 161-165.

11. Pleshakov A. M., Shkabin G. S. Problemy nauchnykh izyskaniy v sfere vzaimosvyazi ugolovnogo prava i operativno-razysknoy deyatel'nosti / Ugolovnoye pravo i operativno-razysknoye zakonodatel'stvo: problemy mezhdu otraslevykh svyazey i perspektivy sovershenstvovaniya: materialy IV mezhvedomstvennoy nauchno-prakticheskoy konferentsii (Ryazan, 30 noyabrya 2018 g.) / otv. red. V. P. Kuvaldin. - Moskva : ID «Yurisprudentsiya», 2019. - S. 85-89.

( ) Никуленко А.В., 2019

Статья поступила в редакцию 12.11.2019 г. 